\title{
Towards Ecological Civilization: Ideas from Azerbaijan
}

\author{
Urkhan Alakbarov'1, John E. S. Lawrence ${ }^{2}$ \\ ${ }^{1}$ The Academy of Public Administration under the President of the Republic of Azerbaijan, Baku, Azerbaijan \\ ${ }^{2}$ International and Public Affairs, Columbia University, New York, USA \\ Email: alakbarovuk@gmail.com, jeslawrence@att.net
}

Received 13 July 2015; accepted 22 August 2015; published 25 August 2015

Copyright (C) 2015 by authors and Scientific Research Publishing Inc.

This work is licensed under the Creative Commons Attribution International License (CC BY).

http://creativecommons.org/licenses/by/4.0/

(c) (i) Open Access

\section{Abstract}

This discussion/review article traces relationships between an innovative strategic, national approach to national human resources development and enhancing national capacity for a more ecologically knowledgeable, sensitive society in a former Soviet country. With stunning speed following independence, Azerbaijan managed its extractive industries (oil and natural gas) effectively, rising to the top globally in annual GDP growth. Its determination to translate "black gold to human gold (BGHG)" and to diversify its economy led to a broad decade-long effort to modernize linkages between education, training and livelihood preparation. A complex national strategy to achieve BGHG was put in place, involving among other components, national labor force surveys, accelerated skills development, and employment service reforms. Given the pressing need for cleanup of Soviet industrial detritus, as well as emerging awareness of environmental responsibility among all sectors, unique "eco-civil" initiatives were launched both in schools and in civil service training programs. The resulting mosaic of public and private sector cooperation in meeting the twin goals of BGHG and a more "eco-civil" society can serve as a model for the region and beyond.

\section{Keywords}

Development, Ecological Civilization, Energy Efficiency, Resources Management, Climate Change

\section{Introduction}

In only the first quarter century after the breakup of the Soviet Union, Azerbaijan has impressed the Caucasus region and the world with its progress. Although it still must work diligently to enhance citizen inputs into its governance structures, continue to expand its productive capacity beyond the energy sectors, and distribute its 
new wealth equitably among its entire population, the country has faced the complex challenges of independence with a mostly steady hand. Much has been achieved in rediscovery of a proud national identity, new resource abundance, sound transportation infrastructure, and a thriving capital city that is now a vibrant modern regional hub.

Among the most important next steps for policy priority over the coming decades will be in sustaining the progress already made with continuing "greener” approaches to development, and increasing diversification of the economy beyond just the oil and natural gas sectors. Initiatives already in place have started along this road, but will need to be strengthened over time. The purpose of this discussion paper, which is based on the in-country practical experience of the authors, is to outline some key characteristics of these improvements in national socio-economic advances, both as a tally of Azerbaijan's record of experience in these areas, and also to offer signposts as other countries contemplate similar steps in the region and beyond. We focus particularly on two aspects of national policy, first the recent emphasis on development of human resources, and then what is referred as ecological civilization or, in short, "eco-civility”, the cultural "greening” of a society through policy-driven adaptation and change. This new concept of “eco-civil (ecological civilization)” as a term was first suggested in the last decade of the $20^{\text {th }}$ century [1] and specified the necessity of combining an optimal proportion between population size and growth, and a consumption culture, while "greening" both social and economic development. Empirical measures of greening are offered, and Azerbaijan's performance on the measures documented as an example.

\section{Pioneers in Human Resources Development}

An important part of Azerbaijan's swift and spectacular progress has been its attempts at synchrony between a developed marine and land-based infrastructure (formerly under Soviet dominance) and its abundant economic resources, not only in a thriving agricultural sector with legendary fruit, nuts and other vegetables, but of course, its oil and natural gas. The international engineering triumph of the more than one thousand mile long Baku-Tbilisi-Ceyhan (BTC) and other different pipelines and roads have transformed the Azerbaijan economy, and sustained national development for at least a decade.

Struck however by the imminent prospect of the "Dutch disease" [2], the Government of Azerbaijan and the United Nations collaborated in a series of projects designed to alleviate negative effects of over-dependence on a single revenue sector. Originally focused on a national employment strategy, these initiatives turned into a bellwether approach to developing human resources as a priority public policy objective. This was an extensive process, involving systematic labor force analysis, review of occupational trends and educational opportunities within a strategic national framework.

The United Nations system had initiated these concepts a decade earlier, first in the Asian region, partly due to the economic promise in several nations, known later as the Asian Tigers [3]. The Jakarta Plan of Action [4] laid out a blueprint for a human perspective of the development process as a whole. This was the first time since Harbison [5] that a systems approach had been applied to the intersections between crucial sectors in human development. A basic premise of the Plan was that the further sustainable development of the Asian and Pacific region would be closely dependent upon both the effective use of the region's human resources and their continued enrichment, through education, skills formation, improved health and nutrition, and other means. It was not surprising therefore that an illustrious Asian himself, Mahbub ul Haq, inaugurated the first Human Development Report two years later for the United Nations Development Program (UNDP) [6]. In that 1990 report, human resources development (HRD), despite arguments by the present author as to its importance as an organizing theme for the relationship between people and their livelihoods, was subsumed (on Page 11) back in its traditional role of human capital formation. At around this time, the idea of sustaining individual livelihoods was beginning also to take form.

"A livelihood comprises the capabilities, assets (including both material and social resources) and activities required for a means of living. A livelihood is sustainable when it can cope with and recover from stress and shocks and maintain or enhance its capabilities and assets both now and in the future, while not undermining the natural resource base." [7].

Further research [8] and discussion [9] led to re-assessment of HRD throughout UN agencies on a broader, more intersectoral framework which could lead to closer and more strategic integration of key constituencies (education, labour, health, and information/communication technologies). At issue is a lack of an integrated pol- 
icy "platform” across key public agencies that can support human "resourcefulness” throughout an individual's lifetime. The UN Secretary-General's Report on HRD to the General Assembly in 1993 [10], authored by UNDP specialists, drew a new blueprint for HRD, outlining five interacting components as major building blocks for anchoring public policy to more cohesive national strategies that facilitate, rather than obstruct equitable human progress at all levels, national to local:

a) Promotion of lifelong acquisition of knowledge, skills and competencies necessary for the performance of chosen roles that contribute economically and socially to self and others;

b) Enhancing opportunities for application of knowledge, skills and competencies in chosen roles (whether through remunerated work or other livelihood activities) in rewarding ways;

c) Improving access to assets (such as land, shelter, capital and information) without which the development of human capabilities is often essentially stunted at the source;

d) Sustenance of human resources through policies and regulatory mechanisms that underpin broad intersectoral support for both the acquisition and the application of knowledge and skills; and

e) Ensuring a modicum of the sense of individual, local and national security: via peaceful political and favorable national and international economic conditions.

Underlying each of these the crucial principle of mutuality, seeking and promoting mutual advantages between individuals and their families, civil society, government, as a public policy priority. Country-to-country variation was explicitly acknowledged as inevitable for nations to adapt these strategic principles to their own conditions. However an overarching definition of integrated HRD was offered [11], following Lawrence (1992 op. cit.) as:

"fostering the contributory capacities that human beings bring to the improvement of their own quality of life and that of others in their families, communities, enterprises and societies. Comprehensive strategies for the development of such human resourcefulness include policies and programmes that promote the acquisition and application of knowledge and skills in ways that are mutually beneficial to individuals and the social groupings of which they are a part".

There has been no substantial revision to this definition in these reports. The integrated, cross-sectoral policy framework it implies (and mutualities between individuals and their chosen social groupings) has been refined over the decades by UN agencies into a strong underpinning for HRD strategies in other countries [12], including Azerbaijan. In 2004, under leadership of Juan Somavia, former Chairman of the Preparatory Committee for the 1995 Copenhagen World Summit for Social Development, the ILO published a new Recommendation 195 [13] on HRD which began to link workforce training and competencies more generically to lifelong learning and adaptability, in particular underscoring relationships between "the interests of individuals, enterprises, the economy and society as a whole”. This recommendation also emphasized social inclusion, “decent work", competitiveness and innovation in the context of a rapidly globalizing economy. As of 2015, the United Nations website on HRD [14] demonstrates that the UN system continues to ground, and document its approach to HRD based on country experience through the biennial reports of the UN Secretary General. For example, a recent WIKI Page [15] summarizes aspects of the current field of national human resources development (NHRD) research and practice, and useful comparisons have already been made as to the adoption and implementation of NHRD strategies in OECD countries [16].

Among subsequent national initiatives was the one in Azerbaijan known as "Black Gold to Human Gold (BGHG)" [17]. Originally a collaborative endeavour between UNDP and the Government of Azerbaijan, examining the skills/jobs outlook for young Azerbaijanis and options for public employment policy, it became embraced by the country's President Aliyev in several speeches, including his presentation to the Baku Humanitarian Forum in 2013. Government commitment is clear. As the President's spokesman said in a recent (March 2014) interview with the New Times,

"You may know that one of the major priorities of our state policy is to transform 'black gold into human gold'. The government is implementing consistent efforts toward bolstering information and knowledge centered human resources. New educational institutions are being inaugurated, and [the] science and education system is being enhanced. In the meantime, state scholarships on education abroad are being realized [18]".

The UNDP Administrator Helen Clark noted in her October 24th 2014 address to the Baku International Humanitarian Forum that the UN system had welcomed the chance to assist Azerbaijan in this pioneering approach. It remained, she said, as relevant as it was when it was launched, and in continuing to lift human development, critical for the achievement of Azerbaijan's national development strategy, Vision 2020. The initiative focused 
on developing an internationally competitive non-oil sector, and developing and strengthening the capacities of Azerbaijani citizens in contributing to a more diversified economy. Over the years, Azerbaijan has seen a drastic reduction in the level of poverty, new investments in social services, the establishment of a social security system, and rising salaries. Yet economic diversification remains a major challenge, since public sector is still the major employer, and the energy sectors share in the economy has persisted stubbornly higher than the cumulative total for all non-oil sectors [19].

One of several project recommendations implemented by the government has been in the arena of accelerated skills development at the post-secondary level. A Presidential Decree Number 2090 (April 16, 2007) in its second paragraph authorized an eight year State Program on Education of Azerbaijani Citizens Abroad. Financed by the State Oil Fund (SOFAZ), this initiative was initially managed within the Ministry of Education. As of April 2014, since 2008 SOFAZ had supported more than 2300 students at college level overseas in mostly UK institutions, in fields varying from medicine, to economics and business at a cost of more than 90 million manats (>US \$100 m) [20]. An interesting aspect of this endeavor is evidence of acknowledgment that responsibility for HRD strategies must be multisectoral. The Caspian Information Center (2011 [21]) in linking health, education and economic sectors under BGHG, states: "some of Azerbaijan's best and brightest students attend universities abroad. Under a scheme sponsored by the Azerbaijani Ministry of Economic Development, students have their fees and costs met by the Government in return for a commitment to return to Azerbaijan to work for a minimum of five years. In 2009, the funds available for students studying abroad was increased by 30\%”.

Other factors driving multisectoral public policy for sustainable livelihoods include new awareness of not only socio-economic, but planetary variables governing our existence. Indispensable in a systems approach to HRD is much better understanding of the environment in which we are all embedded. The most recent HRD Report of the UN S-G [22] focuses

"on how science, technological knowledge and innovation and human resources development can interface in mutually reinforcing ways towards a virtuous circle of economic growth and human and social development”.

In particular, the report notes how this integrated approach is, and will continue to be critical in addressing environmental degradation, climate change, energy sustainability, food insecurity and disaster impact. The remainder of this paper examines the efforts in Azerbaijan to address the concept of ecological civilization, briefly "eco-civil" as it relates to the development of human resourcefulness.

\section{Working towards Ecological Civilization}

The world is moving now beyond awareness, towards some preliminary degree of capable management of what appears to be an imminent, existential climatological threat to human life on this planet. The state of natural resources consumption and environmental degradation has reached a point where it threatens not only the present but also the future generations. Well documented in all regions [23], these challenges present a complex and intersectoral scenario:

"Warming of the climate system is unequivocal, and since the 1950s, many of the observed changes are unprecedented over decades to millennia. The atmosphere and ocean have warmed, the amounts of snow and ice have diminished, sea level has risen, and the concentrations of greenhouse gases have increased" (p. 4).

Such issues require deep social change, not only in public policy, but in intergenerational communication across traditional cultural lines. Around all environmental interactions, governmental (bureaucratic) structures, institutions, schooling, and "normal" human behavior at all levels must be addressed in new ways, and with confident fresh voices. In the Asian region, a process of "green transformation and transition” has been outlined at a recent Chinese conference by the Canadian International Institute for Sustainable Development as a step towards "building eco-civilization" [24]. The forum emphasized green industry, green urbanization, and committed to acting as an initializing platform for open dialogue and working to bridge effective solutions for China's big transformation to an eco-civilization, and eco-civility as a social goal.

Azerbaijan has embraced these concepts in many ways, one of which has been through civil service training. Residual pollution from former Soviet industrial production plants is exacerbated by both the scope of the problem and its concentration. Sumgayit, for example, just north of the capital city Baku, was home to one of the largest chemical industrial sites in the former USSR, presenting major environmental cleanup problems to the Azerbaijani government. "Eco-civil” capacity development in government ministries thus took on a new urgency. Training programs were designed and implemented that focused on professional development around modern philosophy and practice in environmental management [25]. Translated into English, the approach is de- 
scribed as embracing ecological civilization principles, ecologically friendly "green” technologies implementation, ecologization of the human life style and human behavior, and "green" mentality formation.

Figure 1 illustrates the conceptual model driving these eco-civil formation factors, based on education, including in-service training efforts and awareness of population. The sequence is clear of the all stages, though they are interconnected as elements in an open system of progress towards eco-civility. Azerbaijan has acknowledged the difficulties in realizing its objectives, both in creating these cultural adjustments, and in reaching greener industrial and social norms. Full scale implementation of the principles in Figure 1 is of course an ongoing task, to be integrated into national HRD strategies.

Table 1 details the principal components of ecological civilization [26], the ultimate goal of both ecologization (the actions required to "green" public sector policies and practice) and eco-civility (the greening of an entire culture).

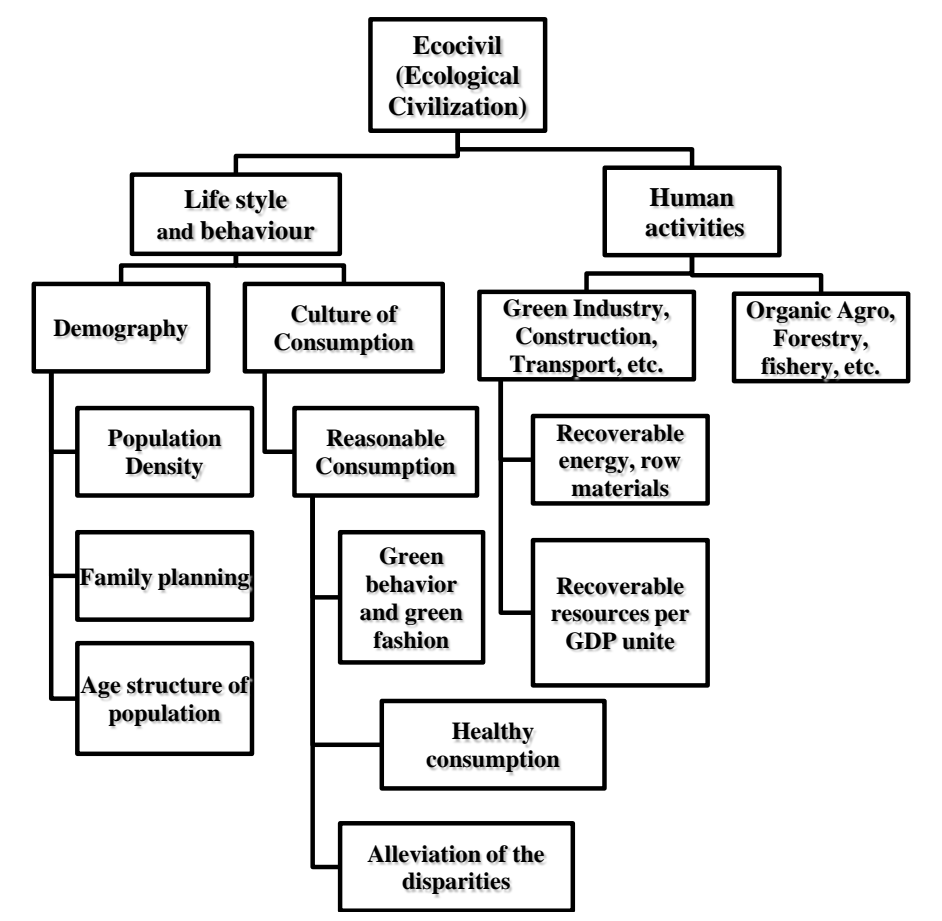

Figure 1. Ecological civilization: concept and elements [1].

Table 1. Principal components of ecological civilization.

\begin{tabular}{|c|c|c|}
\hline \multirow{4}{*}{ Ecologization } & Industry/construction & $\begin{array}{l}\text { Implementation of the green technologies in extracting and manufacturing industries. } \\
\text { Addressing all problems related with industrial emissions and discharges. } \\
\text { Green settlements, green houses constructing and equipping (bio-fuel, } \\
\text { biodegradable materials, green construction technologies, equipments, devices, etc.). }\end{array}$ \\
\hline & Agriculture & Development of organic agriculture, sustainable forestry, fishery, etc. \\
\hline & Transport & $\begin{array}{l}\text { Energy saving, recoverable energy, "zero discharges". } \\
\text { Decreasing the share of public transportation in emission contributions }\end{array}$ \\
\hline & Education & Mandatory green education on primary, secondary and tertiary levels. \\
\hline \multirow{3}{*}{ Demography } & $\begin{array}{l}\text { Number and density } \\
\text { of population }\end{array}$ & Demography and birth rate, optimization of population density and settlements sizes. \\
\hline & Health & Decreasing risks factors and increasing of the anti-risk factors for long and healthy life. \\
\hline & Quality of life & Natural, economical, political, social environment providing prosperity with equity. \\
\hline Consumption & Culture of consumption & $\begin{array}{l}\text { Consumption on the level of reasonable needs. Life style and consumption patterns } \\
\text { for management of any existing and potential risks for long, healthy and creative life, } \\
\text { based on combination of the most updated scientific research with historically } \\
\text { accepted ethnic/local knowledge and culture. Public policy on biodiversity } \\
\text { conservation interlocked with reduction of social disparities. }\end{array}$ \\
\hline
\end{tabular}


In the fourth row under "ecologization", education is introduced as a principal component. In this field, Azerbaijan has been at the forefront of global efforts. In addition to the ecocivl "learning tools" prepared for civil service capacity development, new curricula and specialized textbooks have been introduced since 1997 at secondary and tertiary levels throughout Azerbaijan. In some cases these were the world's first [27], and innovatively tie together global environmental themes with local cultural traditions emphasizing conservation, biodiversity and sustainable management of natural resources. UNDP and UNESCO included these Azerbaijan examples in its catalog of good practices in the region [28]. A recent independent evaluation of teaching and applying modern human development concepts at tertiary levels in Azerbaijan documents the achievements and quality of these programs at the Academy of Public Administration and two other universities [29].

Finally, it is important to note the progress made by Azerbaijan in its pursuit of sustainable development in practice. Between 2000 and 2013, Azerbaijan's value on the UNDP Human Development Index increased from 0.639 to 0.747 , an increase of 17.0 percent or an average annual increase of about 1.21 percent [30]. In addition to an innovative employment service office, new industries have opened up in Sumgayit designed explicitly around environmentally friendly principles [31]. For example, a new cardboard and paper processing factory is fully automated, making the facility unique in the Caucasus region in the use of recycled products. It employs 150 people, and turns out 50,000 tons annually. Modern technology used in the production process is expected to:

"Prevent the cut of 850,000 conifers per year, the destruction of forests, and hazardous substance emission. Ninety percent of the company's needs for raw materials will be met by blanking paper waste".

There are also new copper processing, and cooking oil plants, both using state-of-the-art technologies and equipment, enhancing employment opportunities and exhibiting national commitment to sustainable industrial development in one of the formerly most severely degraded worksites in the world.

Furthermore, statistical evidence is available of Azerbaijan's progress in pursuing more eco-civil goals. It can be shown that the nation's efficiency of energy use is much higher than the world average [32]. Using an index that shows the consumption of energy in relation to GDP, with data from 2000 to 2012, Azerbaijan is compared to global averages on the same measures. Until 2009 the economic efficiency of energy use lagged significantly behind the average world figures. Beginning in 2009, however, Azerbaijan's figures pulled ahead of the world average and by 2011 the volume of goods and services produced in the country per energy unit was $23 \%$ higher than the world average. It is worth looking at this remarkable achievement in closer detail.

As we have argued, rational management of recoverable and non-recoverable resources is an important indicator of the sustainability of development processes, and can point towards, and conceivably result in, efficiencies in human development policy. Quite simply, effective use of energy resources over the longer term is essential for sustainable development. When countries seek to build a culture of sustainability, they promote these kinds of advances. Azerbaijan has contributed to innovative, empirical application of various methods used in evaluating whether these resources are used to best effect, for example the index showing the consumption of energy needed to produce gross domestic product (GDP). Two characteristics of this index are used in international statistics [33]. One of them demonstrates the value of goods and services, produced using each unit of consumed energy. In order to make a comparison between countries or regions using this method, it has been internationally accepted to use the quantity of energy contained in $1 \mathrm{~kg}$ of oil as an energy unit. The average cost per kg of oil during a particular year is the same throughout the world. This methodology, therefore, and the application of this equivalent of energy makes it possible to assess energy efficiency even when the energy type has been received from different sources. The cost of goods and services produced with the volume of energy equivalent to the amount of energy in one kilogram of oil can be calculated generically in US dollars [34]. A second evaluation method implemented by international organizations compares the amount of energy needed to produce US \$1000 of GDP. Both methods underscore the importance of efficient planning and management of natural resources, in order to maintain sustainable development and a green economy.

According to World Bank data, energy efficiency in Azerbaijan increased during the last decade by more than 2.5 times (from US $\$ 4.0$ per $1 \mathrm{~kg}$ oil equivalent in 2003 and US \$11.5 in 2012). By contrast, the world average figure (for 2012) was 7.3 USD per unit of energy use. For G7 countries this figure was 8.3 USD per unit of energy used [34]. So, by these measures, energy efficiency in the young nation of Azerbaijan is higher than in many G7 countries and above average for this group of countries. This happened because growth rates in the efficient use of energy resources in the Republic of Azerbaijan during the last decade were higher than the growth in average world indicators. Azerbaijan policies during this period were directed towards human capacity build- 
ing, expanding the knowledge and abilities of civil servants and policy makers who were working in development planning and management. The figures for G7 countries (USD PPP 2011 per I kg oil equivalent) is as follows: Canada 5.7, USA 7.5, France 9.4, Japan 9.9, Germany 11.0, UK 11.5, Italy 12.7. G7 countries average 8.6, and the Republic of Azerbaijan is 11.5

Since Azerbaijan's increase in the efficient use of energy resources is largely tied to factors in the sector of the country's economy associated with the production and export of oil and gas, it is also useful to compare this measure more specifically with other predominantly extractive economies. Relevant indicators of major oil and gas producing and exporting countries, including Azerbaijan, show that during 2003-2011 (latest data available) all countries exporting hydrocarbons increased their energy efficiency. However, Azerbaijan has been a standout here. In 2003 the World Bank reports that the Republic of Azerbaijan took one of the last places among the reference countries, but by 2013 was in second place behind Norway among the reference countries in terms of rational management of energy resources for GDP production. As of 2014, energy efficiency for GDP production in Azerbaijan is actually higher than in Norway [34].

\section{Conclusion}

The planning, experience and results documented in this paper are emphatically hypothetical. While it is tempting, and perhaps reasonable to conclude this all happened because of implementation of policies directed towards expanding knowledge and abilities of civil servants and policy makers who were working in development planning and management, clearly more analytical and research work are required to establish the systemic connections we suggest. But the movement in Azerbaijan towards broader development objectives, economic diversity and equitable distribution of wealth continues, and is important as a case study in itself. In particular, the relatively new concept of eco-civility in standard educational practice is crucial for not only national progress but serves as a model for the region and beyond. Reinforcement for this trend can therefore be hypothesized as emerging from not only building a more aware public, and student exposure through the national textbook program devoted to sustainable development, but mandating it as a governmental priority. Certainly, more study is needed to establish causality in this progress. Yet we suggest these data are encouraging, and point in new directions towards successful adoption of strategic national approaches to developing human resourcefulness and eco-civility.

\section{References}

[1] Alakbarov, U.K. (1998) Ecologization of Human Activity. J. Energy, Ecology, Economy, 2, 141-143.

[2] Financial Times. http://lexicon.ft.com/Term?term=dutch-disease

[3] Leipziger, D.M. and Thomas, V. (1993) The Lessons of East Asia: An Overview of Country Experience. World Bank, Washington DC.

[4] United Nations (1988) Economic and Social Commission for Asia \& the Pacific (ESCAP). The Jakarta Plan of Action, Bangkok.

[5] Harbison, F. (1967) Systems Analysis Approach to Human Resource Development Planning. Fundamentals of Educational Planning, International Institute of Educational Planning, UNESCO, Paris.

[6] (1990) United Nations Development Program. Human Development Report, New York.

[7] Chambers, R. and Conway, G. (1991) Sustainable Rural Livelihoods: Practical Concepts for the 21st Century.

[8] Lawrence, J.E.S. (1992) Literacy \& Human Resources Development: An Integrated Approach. Annals of the American Academy of Political and Social Sciences, 520, 42-53.

[9] (1994) Changing Perspectives on Human Resources Development. Report of the United Nations Expert Group Meeting on Human Resources Development in the Public Sector. United Nations Headquarters, New York.

[10] (1993) Report of the UN Secretary-General on Human Resources Development.

[11] (1995) UN Secretary-General's Report on HRD. 4.

[12] Human Resource Development Strategy for South Africa (HRD-SA). 2010-2030.

[13] (2004) R195-Human Resources Development Recommendation, 2004 (No. 195). Recommendation Concerning Human Resources Development: Education, Training and Lifelong Learning. 92nd International Labour Conference Session, Geneva.

[14] http://www.un.org/en/development/desa/oesc/humanresources.shtml 
[15] http://en.wikipedia.org/wiki/National_human_resource_development

[16] Oh, H., Choi, Y. and Choi, M. (2013) Comparative Analysis of OECD Member Countries' Competitive Advantage in National Human Resource Development Systems. Asia Pacific Education Review, 14, 189-208. http://dx.doi.org/10.1007/s12564-013-9255-z

[17] Hopkins, M., Lawrence, J.E.S., Stephens, T. and Webster, A. (2008) Converting Black Gold into Human Gold: Using Oil Revenues to Achieve Sustainable Development. Baku.

[18] Mammadov, N. (2014) Deputy Head of the Presidential Administration of the Republic of Azerbaijan and Head of Foreign Relations Department. New Times, Baku.

[19] Bayramov, V. (2014) Diversification of Azerbaijan’s Economy; Ways to European Integration. Center for Economic and Social Development, Azerbaijan.

[20] Government of Azerbaijan (2014) Information on Implementation of the "State Program on Education of Azerbaijani Youth Abroad for the Years of 2007-2015. Baku, 1 April 2014.

[21] Caspian Information Center (2011) Turning Black Gold into Human Gold: Education and Health Care in Azerbaijan. Occasional Paper, No. 9.

[22] (2013) UN Secretary General’s Report on Human Resources Development. A/68/228.

[23] Intergovernmental Panel on Climate Change (2013) Climate Change 2013: The Physical Science Basis. Cambridge University Press, Cambridge.

[24] Mark, H. (2013) Building Eco-Civilization: Green Transformation and Transition. Eco-Forum Global in Guiyang, Guizhou.

[25] Alakbarov, U. (2013) From Sustainable Development to an Ecological Civilization: The Problem of Training of the Civil Service. Academy of Public Administration, Baku.

[26] Alakbarov, U.K. and Imanov, G.C. (2011) Ecological Civilization Index: Concept and First Implementation. Proceedings of the Azerbaijan National Man and the Biosphere Committee, UNESCO, 7, 5-13.

[27] Alakbarov, U. (2007) “Eco-Civil” Concept in Textbooks and Readings on Sustainable Human Development Published in Azerbaijan from 2003-2007. UNESCO Proceedings of Euro MAB, Turkey, 63-65.

[28] (2007) Good Practices in Education for Sustainable Development in the UNECE Region, UNESCO, Paris.

[29] Madhoun, W. (2013) Strengthening the Capacity of Educational Institutions for Teaching and Applying Human Development Concepts. Final Evaluation, UNDP, Baku.

[30] United Nations Human Development Report 2014: Sustaining Human Progress: Reducing Vulnerabilities and Building Resilience.

[31] Azer News. 27 February 2015.

[32] Alakbarov, U. (2014) Effective Management of Resources to Support Sustainable Development and Move towards Ecological Civilization: Experience of the Republic of Azerbaijan. Journal of Human Resource and Sustainability Studies, 2. 131-135.

[33] UNDP (2014) Human Development Report, New York, 225.

[34] World Bank (2014) World Development Indicators \& Global Development Finance. http://data.worldbank.org/data-catalog/world-development-indicators 